\title{
Initial Development and Reliability of a Motivation for Weight Loss Scale
}

\author{
Andrea H. Meyer ${ }^{a, b}$ Simone Weissen-Schelling ${ }^{b}$ Simone Munsch $^{c}$ Jürgen Margraf ${ }^{b}$ \\ a Division of Applied Statistics in Life Sciences, \\ ${ }^{\mathrm{b}}$ Department of Clinical Psychology and Psychotherapy, Faculty of Psychology, University of Basel, \\ ${ }^{\mathrm{c}}$ Institute of Psychology, Clinical Child and Adolescent Psychology, University of Lausanne, Switzerland
}

\section{Keywords}

Appearance $\cdot$ Health - Overweight - Obesity . Questionnaire development . Weight loss motivation

\section{Summary}

Objective: We aimed at developing and evaluating a questionnaire assessing health and appearance as the two main reasons for weight loss in overweight and obese individuals. Methods: Using data from two representative telephone surveys in Switzerland, the factorial structure of this questionnaire was analyzed by exploratory and confirmatory factor analysis. The model obtained was cross-validated with data from a second representative Swiss survey and multigroup analyses according to sex, age, BMI and regional language subgroups were performed. Results: This lead to a 24-item, 3-factor solution, with factors labeled 'health', 'appearance in relation to others', and 'appearance in relation to oneself'. Internal consistency and test-retest reliability were good. Conclusions: To the best of our knowledge, this is the first validated questionnaire assessing overweight and obese individuals' reasons for weight loss. It should be further tested whether using this questionnaire as a pretreatment assessment device will help in tailoring treatments to individuals, thereby increasing treatment adherence and success.

\section{Introduction}

In the past few decades, overweight and obesity have reached epidemic proportions worldwide [1]. As both are associated with increased morbidity in the areas of physical and mental health [2-4], health care costs for weight-related illnesses are soaring [5]. Moreover, overweight and obesity are associated with decreased quality of life [6-7], lower socioeconomic status [8] and stigmatization [9], leading to an economic as well as psychological burden for societies and individuals all over the world.

Previous research has shown that weight loss is an important concern for many of the individuals affected by overweight and obesity, with women trying to lose weight at a lower BMI than men [10-12]. Despite the fact that many individuals want to lose weight and many treatment options are available, weight loss treatments are only of moderate success in the short and long term [13-15], and dropout rates are usually high [16-17]. Therefore, it is important to understand the factors contributing to treatment adherence and success. Guidelines [18] suggest that reasons and motivation for weight loss represent meaningful characteristics of patients that should be assessed prior to any weight loss intervention in order to identify those individuals who are really ready that is, motivated - for weight loss and those who are more ambiguous and at risk of dropping out of treatment.

Data from weight loss intervention studies and telephone surveys indicate that the perception of obesity as a health risk $[19,12]$ and dissatisfaction with own appearance [20-23] are the two main motivating factors for weight loss attempts in about $50-85 \%$ and $15-36 \%$ of overweight and obese individuals, respectively [21-23]. Individuals citing either health or appearance as their number one reason for weight loss differ in regard to self-esteem [23-24], body dissatisfaction [22-24], and their BMIs [23]. Moreover, motivating factors for weight loss seem to differ with age $[19,24]$. A qualitative report covering people's reasons for entering a weight loss regime [25] found that those who were most successful in losing a significant amount of weight were most likely to indicate health as reason for weight loss.

\section{KARGER}

Fax +49 7614520714

Information@Karger.de

www.karger.com (c) 2010 S. Karger GmbH, Freiburg

Accessible online at:

www.karger.com/ofa
Dr. Andrea H. Meyer

Division of Applied Statistics in Life Sciences

Department of Clinical Psychology and Psychotherapy

Faculty of Psychology, University of Basel

Missionstrasse 60/62a, 4055 Basel, Switzerland

andrea.meyer@unibas.ch 
Thus, despite the urgent need to enhance treatment outcomes in overweight and obese patients and the often-cited impact of an individual's motivation for weight loss on treatment success, there is a lack of reliable and valid assessment devices in this area of research. The best-known measure assessing a person's willingness and preparedness to engage in the behavioral practices required to lose weight is the Dieting Readiness Test (DRT) [26]. However, this scale assesses readiness for weight loss on different dimensions but not a person's reasons for losing weight. Moreover, although research studies agree that health and appearance are the two main reasons for weight loss, there is no indication of how they are correlated.

The aim of the present study therefore was to develop and evaluate a questionnaire that considers health and appearance as different aspects of motivation for weight loss. By using this questionnaire as a pretreatment assessment device, a person's motives for weight loss can be identified, and a weight loss program's components could be tailored to the individual, thereby enhancing treatment success and reducing the usually high dropout rates.

\section{Participants and Methods}

\section{Participants}

In 2004, two telephone surveys were conducted to obtain representative samples from the German- and French-speaking parts of Switzerland. In both surveys, participants were selected according to the random-quota method, with age, sex, geographical region, and size of community being the quota characteristics. Participants were selected from the database of current landline telephone accounts. To be included in the survey, participants had to be between 15 and 74 years of age. Participation was voluntary. In the first survey, conducted in January 2004, 1,000 participants were interviewed. In the second survey, conducted in June 2004, the corresponding sample size was 800 . For our analysis we used the interviewees reporting a $\mathrm{BMI}$ of $\geq 25 \mathrm{~kg} / \mathrm{m}^{2}$, that is 355 (36\%) from survey 1 and 232 ( $29 \%$ ) from survey 2 . The interviewees of survey 2 were re-interviewed 1 week later, where 140 of them participated again, corresponding to a response rate of $60.3 \%$. Sample characteristics are displayed in table 1.

\section{Procedure}

Both telephone surveys were conducted by IHA GfK AG, a professional research institute in Switzerland. In survey 1, the questionnaire consisted of 39 questions concerning height, weight, reasons for wanting to lose weight, dieting history, binge-eating episodes, physical activity and several sociodemographic characteristics. In the first wave of the second survey questions concerning height, weight and reasons for wanting to lose weight as well as several sociodemographic questions were asked, whereas in the second wave only the questions concerning reasons for wanting to lose weight were presented. For the construction and validation of our questionnaire only questions concerning reasons for wanting to lose weight were analyzed. These questions were exactly the same in both surveys and in both waves of survey 2 with respect to the number asked and the phrasing.

\section{Scale Construction}

We used a deductive scale development strategy based on theoretical considerations. After a thorough review of existing literature regarding
Table 1. Sample characteristics of overweight and obese interviewees of surveys 1 and 2

\begin{tabular}{|c|c|c|c|}
\hline Variable & $\begin{array}{l}\text { Survey } 1 \\
(\mathrm{~N}=355)\end{array}$ & $\begin{array}{l}\text { Survey } 2 \text {, } \\
\text { first wave } \\
(\mathrm{N}=232)\end{array}$ & $\begin{array}{l}\text { Survey } 2, \\
\text { second wave } \\
(\mathrm{N}=140)\end{array}$ \\
\hline Gender, $\%$ female & 35.8 & 38.4 & 42.1 \\
\hline $\begin{array}{l}\text { Language region, \% } \\
\text { German speaking }\end{array}$ & 73.2 & 73.7 & 81.4 \\
\hline Mean age, years (SD) & $48.3(14.8)$ & $49.5(14.6)$ & $50.1(14.1)$ \\
\hline Mean BMI, $\mathrm{kg} / \mathrm{m}^{2}(\mathrm{SD})$ & $28.3(3.8)$ & $29.0(3.6)$ & $28.7(2.8)$ \\
\hline \multicolumn{4}{|l|}{ Employment status, \% } \\
\hline Full time & 47.9 & 43.5 & 43.6 \\
\hline Part time & 16.9 & 16.4 & 18.6 \\
\hline Unemployed $^{\mathrm{a}}$ & 35.2 & 40.1 & 37.9 \\
\hline \multicolumn{4}{|l|}{ Educational attainment, \% } \\
\hline Primary or lower & 16.3 & 13.8 & 14.3 \\
\hline Secondary/upper & 70.7 & 66.0 & 67.1 \\
\hline Secondary/tertiary & 12.9 & 20.2 & 18.5 \\
\hline \multicolumn{4}{|l|}{ Living situation, \% } \\
\hline Family & 49.4 & 45.3 & 45.0 \\
\hline Couple & 36.4 & 41.4 & 41.4 \\
\hline Single & 14.4 & 13.4 & 13.6 \\
\hline
\end{tabular}

${ }^{a}$ Mostly retired persons, housewives and students.

obese individuals' motivational reasons for weight loss [19, 22-25], we generated a wide array of possible reasons for weight loss that could be allocated to either the health or appearance motive. This pool of 39 items was then presented to the interviewees (each item consisting of the statement 'I want to lose weight ...', followed by a different weight loss reason). All items had to be answered on a four-point Likert scale with the values 1: 'absolutely not', 2: 'somewhat', 3: 'moderately' and 4: 'strongly', indicating how much participants identified with the different statements.

\section{Statistical Analysis}

\section{Data Preparation}

Of the 355 overweight and obese participants captured in survey 1, 25 datasets contained at least one missing answer and were eliminated, leaving a total of 330 observations for subsequent analysis. For the same reason we eliminated 17 participants from the first wave of survey 2, leaving a total of 215 observations for analysis. Data preparation for both surveys included the log transformation of the 39 items to achieve normality and homoscedasticity and the subsequent elimination of 10 (survey 1) and 6 (first wave of survey 2) observations that were either univariate or multivariate outliers [27]. Thus, the sample sizes for the analysis of survey 1 and the first wave of survey 2 were 320 and 209, respectively.

\section{Construction of Final Questionnaire and Evaluation of Scale}

First, exploratory factor analysis (EFA) based on the principal axes factoring method with varimax rotation was used to extract the factorial structure of the questionnaire items [28]. EFA was done using data from survey 1 , and the factorial structure obtained was analyzed using the Kaiser-Guttman criterion, the scree plot and parallel analysis [29] for identification of the number of factors needed. The obtained model was subsequently tested for goodness of fit using confirmatory factor analysis (CFA) and then cross-validated using the data from the first wave of survey 2 . No modifications were made to the model to improve goodness of fit. 
Table 2. Factor loadings of the three-factor solution regarding reasons for wanting to lose weight

\begin{tabular}{|c|c|c|c|c|}
\hline \multirow[t]{2}{*}{ Item no. } & \multirow[t]{2}{*}{ Item label } & \multicolumn{3}{|c|}{$\begin{array}{l}\text { Factor } \\
\text { loadings }\end{array}$} \\
\hline & & I & II & III \\
\hline \multicolumn{5}{|c|}{ Factor I: health } \\
\hline 3. & $\begin{array}{l}\text { Because it is commonly said that being overweight } \\
\text { is unhealthy }\end{array}$ & 0.597 & 0.153 & 0.285 \\
\hline 5. & To be healthier & 0.685 & 0.134 & 0.280 \\
\hline 9. & To be more agile & 0.662 & 0.175 & 0.291 \\
\hline 10. & For health reasons & 0.839 & 0.084 & 0.140 \\
\hline 15. & Because I read that it is healthier & 0.586 & 0.219 & 0.107 \\
\hline 20. & To decrease my health risks & 0.784 & 0.037 & 0.11 \\
\hline 25. & To live long & 0.582 & 0.230 & 0.138 \\
\hline \multicolumn{5}{|c|}{ Factor II: appearance in relation to others } \\
\hline 1. & Because acquaintances have advised me to & 0.127 & 0.622 & 0.154 \\
\hline 4. & To not attract attention & 0.225 & 0.595 & 0.274 \\
\hline 6. & Because I'll be more successful in my job & 0.199 & 0.626 & 0.13 \\
\hline 7. & So I will be accepted by society & 0.177 & 0.747 & 0.209 \\
\hline 8. & To dare to socialize again & 0.072 & 0.717 & 0.254 \\
\hline 12. & Because I would be luckier in love & 0.143 & 0.631 & 0.289 \\
\hline 16. & To be more appreciated/liked & 0.219 & 0.644 & 0.246 \\
\hline 21. & To have more friends & 0.129 & 0.589 & 0.159 \\
\hline 28. & To have better success with others & 0.114 & 0.681 & 0.306 \\
\hline 39. & So that other people will think better of me & 0.042 & 0.727 & 0.217 \\
\hline \multicolumn{5}{|c|}{ Factor III: appearance in relation to oneself } \\
\hline 2. & To be more attractive & 0.288 & 0.258 & 0.611 \\
\hline 14. & To like to look at myself in the mirror again & 0.263 & 0.202 & 0.694 \\
\hline 23. & Because I want to like myself more & 0.130 & 0.309 & 0.678 \\
\hline 27. & Because I want to be more attractive & 0.238 & 0.285 & 0.677 \\
\hline 30. & To be able to dress more fashionably & 0.300 & 0.237 & 0.559 \\
\hline 31. & To fit into my clothes again & 0.194 & 0.402 & 0.551 \\
\hline 32. & To feel more self-confident & 0.288 & 0.258 & 0.611 \\
\hline
\end{tabular}

To test for factor invariance with respect to factor loadings and factor variances and covariances between sex, age, obesity and regional language groups, we performed several multigroup analyses within the CFA framework according to Byrne [30], comparing the following subgroups: male versus female (sex), $<50$ years versus $\geq 50$ years (age), BMI $<30 \mathrm{~kg} / \mathrm{m}^{2}$ versus BMI $\geq 30 \mathrm{~kg} / \mathrm{m}^{2}$ (BMI) and German versus French speaking (language region). To perform EFA and CFA, we used the software packages SPSS 14 [31] and AMOS 5 [32], respectively.

\section{Reliability}

Internal consistency of items within each factor and of all items combined was computed using Cronbach's alpha [33]. To assess the test-retest reliability (stability of measure over time) of the questionnaire, we compared the data sets from the two waves of the second survey. There were 140 valid cases available for both waves. 23 cases were eliminated because they contained at least one missing answer. Data preparation included the $\log$ transformation of the sum of the 24 items for each wave to achieve normality and homoscedasticity, followed by the elimination of another 8 cases that were either univariate or multivariate outliers [27]. The final sample size covering both waves contained 109 observations. We used Pearson's correlation coefficients and intraclass correlation coefficients to assess test-retest reliability for each of the factors obtained as well as for all items combined. In addition, paired t-tests were used to test for changes in mean values between the first and second wave together with repeatability coefficients, defined as 1.96 times the standard deviation of the differences between the values of the first and second wave [34]. Re- peatability coefficients denote the limits within which $95 \%$ of the differences between pairs of measurements are expected.

\section{Results}

\section{Exploratory Factor Analysis}

We first ran an EFA on all 39 items (results available from the authors on request). Subsequently, 15 items had to be removed because they either had factor loadings less than 0.55 or loaded on more than one factor [35]. Running EFA based on the remaining 24 items led to three factors: 'health', 'appearance in relation to others' and 'appearance in relation to oneself' (table 2), with eigenvalues greater than 1 (values between 5.2 and 3.7) consisting of 7, 10, and 7 items, respectively. Parallel analysis confirmed this result. The three factors accounted for $21.6,16.2$, and $15.3 \%$ of the total item variance in the rotated factor solution.

\section{Reliability}

Internal consistencies for factors I-III were $0.88,0.91$ and 0.89 , and 0.93 if all 24 items were combined. Item-total corre- 
Table 3. Fit indices of the unconstrained baseline models of each subgroup

\begin{tabular}{|c|c|c|c|c|c|c|c|c|}
\hline & $\mathrm{N}$ & $\chi^{2}$ & df & CFI & TLI & RMSEA & $\mathrm{P}_{\text {close }}$ & AIC \\
\hline \multicolumn{9}{|l|}{ Full sample } \\
\hline Survey 1 & 320 & 530.5 & 249 & 0.930 & 0.923 & 0.060 & 0.013 & 632.5 \\
\hline $\begin{array}{l}\text { Survey } 2 \text {, first wave, } \\
\text { cross-validated }\end{array}$ & 209 & 571.5 & 249 & 0.899 & 0.888 & 0.079 & 0.001 & 673.5 \\
\hline \multicolumn{9}{|l|}{ Subgroups (survey 1) } \\
\hline \multicolumn{9}{|l|}{ Sex } \\
\hline Male & 208 & 453.2 & 249 & 0.913 & 0.903 & 0.063 & 0.012 & 603.2 \\
\hline Female & 112 & 403.3 & 249 & 0.912 & 0.902 & 0.075 & 0.002 & 553.3 \\
\hline \multicolumn{9}{|l|}{ Age } \\
\hline$<50$ years & 170 & 398.5 & 249 & 0.928 & 0.920 & 0.060 & 0.076 & 548.5 \\
\hline$\geq 50$ years & 150 & 459.0 & 249 & 0.898 & 0.887 & 0.075 & 0.000 & 609.0 \\
\hline \multicolumn{9}{|l|}{ BMI } \\
\hline$<30 \mathrm{~kg} / \mathrm{m}^{2}$ & 255 & 502.8 & 249 & 0.922 & 0.913 & 0.063 & 0.004 & 652.8 \\
\hline$\geq 30 \mathrm{~kg} / \mathrm{m}^{2}$ & 65 & 378.1 & 249 & 0.859 & 0.843 & 0.090 & 0.001 & 528.1 \\
\hline \multicolumn{9}{|l|}{ Language region } \\
\hline German speaking & 237 & 473.6 & 249 & 0.924 & 0.916 & 0.062 & 0.012 & 575.6 \\
\hline French speaking & 83 & 412.2 & 249 & 0.868 & 0.853 & 0.089 & 0.000 & 514.2 \\
\hline
\end{tabular}

$\mathrm{CFI}=$ Comparative Fit Index; TLI = Tucker and Lewis Index; RMSEA $=$ Root mean square error of approximation; $P_{\text {close }}=\mathrm{P}$ for test of close fit $\mathrm{AIC}=$ Akaike Information Criterion. lations for items within each factor ranged between 0.59 and 0.77 and were thus much higher than 0.30 , the value that is considered problematic [36]. Test-retest reliability was high, with correlation coefficients ranging between 0.75 and 0.83 and intraclass correlation coefficients ranging between 0.74 and 0.82. Also, mean differences between the two waves ranged between -0.03 and 0.03 for the three subscales and did not differ from 0 for any of them (paired t-test, $\mathrm{p} \geq 0.20$ for all three subscales). Corresponding repeatability coefficients ranged between 0.19 and 0.28 for the three subscales.

\section{Confirmatory Factor Analysis}

The three-factor model obtained from EFA was tested using the data of survey 1 and resulted in reasonably good fit indices (table 3, first line). Factor loadings varied between 0.59 and 0.83 . Intercorrelations among the three factors were 0.43 (factor I vs. factor II), 0.71 (factor II vs. factor III), and 0.58 (factor I vs. factor III). They were all significantly different from 1 , suggesting sufficient discriminant validity to justify three different scales. In addition, the three-factor model fitted the data significantly better than a model consisting of one factor only $\left(\Delta \chi^{2}=975.9, \Delta \mathrm{df}=3, \mathrm{p} \leq 0.001\right.$, for the difference between the two models).

\section{Cross-Validation}

When the model obtained from CFA was fit to the data of the first wave of survey 2 , the resulting fit was only slightly worse than when using the original data set from survey 1 , suggesting a stable model (table 3, second line). Factor loadings for this model varied between 0.57 and 0.83 . Intercorrelations among the three factors were somewhat higher than for sur- vey 1 with values 0.63 (factor I vs. factor II), 0.78 (factor II vs. factor III), and 0.69 (factor I vs. factor III), but they were still all significantly different from 1 . Again, this model fitted the data significantly better than a model with just one factor $\left(\Delta \chi^{2}\right.$ $=520.7, \Delta \mathrm{df}=3, \mathrm{p} \leq 0.001)$. Internal consistencies for the three factors were $0.91,0.92$ and 0.90 , and 0.95 if all items were combined.

\section{Factor Invariance of the Three-Factor Model}

To test whether the proposed three-factor model was equivalent across subgroups with respect to factor loadings and factor variances and covariances, we first determined goodnessof-fit statistics of the baseline models in each subgroup. Model fits were reasonable for all subgroups except for the subgroups $\mathrm{BMI} \geq 30 \mathrm{~kg} / \mathrm{m}^{2}$ and French-speaking region, where sample sizes were small (table 3 ).

Goodness-of-fit statistics of the three unconstrained twogroup models were all reasonably good (sex: $\chi^{2}=856.9$, df $=$ $498, \mathrm{GFI}=0.82, \mathrm{CFI}=0.91, \mathrm{TLI}=0.90, \mathrm{RMSEA}=0.048, \mathrm{P}_{\text {close }}$ $=0.77, \mathrm{RMR}=0.016$; age: $\chi^{2}=857.6, \mathrm{df}=498, \mathrm{GFI}=0.82, \mathrm{CFI}$ $=0.91, \mathrm{TLI}=0.91, \mathrm{RMSEA}=0.048, \mathrm{P}_{\text {close }}=0.76, \mathrm{RMR}=$ 0.016; BMI: $\chi^{2}=883.2, \mathrm{df}=498, \mathrm{GFI}=0.83, \mathrm{CFI}=0.91, \mathrm{TLI}=$ $0.90, \mathrm{RMSEA}=0.049, \mathrm{P}_{\text {close }}=0.577, \mathrm{RMR}=0.019$; language region: $\chi^{2}=887.3, \mathrm{df}=498, \mathrm{GFI}=0.82, \mathrm{CFI}=0.91, \mathrm{TLI}=0.90$, RMSEA $\left.=0.050, \mathrm{P}_{\text {close }}=0.545, \mathrm{RMR}=0.017\right)$. Constraining all these models to have equal factor loadings did not significantly worsen model fits (table 4). When in addition equal factor variances and covariances between the groups were imposed, model fits again did not significantly worsen for age, BMI and regional language groups. Between males and females, however, we detected invariance with respect to factor 
Table 4. Goodnessof-fit statistics for tests of invariance across groups

\begin{tabular}{|c|c|c|c|c|c|}
\hline Model description & $\chi^{2}$ & df & $\Delta \chi^{2}$ & $\Delta \mathrm{df}$ & Significance \\
\hline \multicolumn{6}{|l|}{ Sex } \\
\hline Unconstrained, combined model & 856.9 & 498 & - & - & - \\
\hline Factor loadings constrained to be equal & 873.0 & 519 & 16.1 & 21 & 0.76 \\
\hline Factor loadings + variances constrained ${ }^{\mathrm{a}}$ & 880.1 & 522 & 23.2 & 24 & 0.51 \\
\hline Factor loadings + variances + covariances constrained & 898.0 & 525 & 41.2 & 27 & 0.040 \\
\hline \multicolumn{6}{|l|}{ Age } \\
\hline Unconstrained, combined model & 857.6 & 498 & - & - & - \\
\hline Factor loadings constrained to be equal & 884.1 & 519 & 26.5 & 21 & 0.19 \\
\hline Factor loadings + variances + covariances constrained & 892.6 & 525 & 35.1 & 27 & 0.14 \\
\hline \multicolumn{6}{|l|}{ BMI } \\
\hline Unconstrained, combined model & 883.2 & 498 & - & - & - \\
\hline Factor loadings constrained to be equal & 904.3 & 519 & 21.1 & 21 & 0.45 \\
\hline Factor loadings + variances + covariances constrained & 916.9 & 525 & 33.7 & 27 & 0.18 \\
\hline \multicolumn{6}{|l|}{ Language region } \\
\hline Unconstrained, combined model & 887.3 & 498 & - & - & - \\
\hline Factor loadings constrained to be equal & 916.6 & 519 & 29.2 & 21 & 0.11 \\
\hline Factor loadings + variances + covariances constrained & 922.2 & 525 & 34.8 & 27 & 0.14 \\
\hline
\end{tabular}

variances and covariances. Separating the effects of equal factor variances from those of equal covariances among factors we found that it was the covariances among the factors, and not the factor variances that differed between males and females (see 3rd and 4th line in table 4). Correlations (i.e. standardized covariances) among factors for males and females were as follows: males: $r=0.41$ (health vs. appearance in relation to others), $r=0.79$ (appearance in relation to others vs. in relation to oneself), $\mathrm{r}=0.50$ (health vs. appearance in relation to oneself); females: $r=0.46$ (health vs. appearance in relation to others), $r=0.65$ (appearance in relation to others vs. in relation to oneself), $r=0.74$ (health vs. appearance in relation to oneself).

\section{Discussion}

The aim of the present study was to develop and evaluate a questionnaire assessing motivation for weight loss in overweight and obese individuals, as there has been up to now a lack of reliable and validated questionnaires in this area of research. Based on factor analysis of responses to telephone interviews in two representative samples of Swiss inhabitants ( $\mathrm{N}=320$ or $\mathrm{N}=209$ ), we constructed a 24-item questionnaire with items loading on three factors that accounted for 21.6, 16.2 and $15.3 \%$ of the total item variance. Results of CFA, internal consistency, test-retest reliability, discriminant validity and cross-validation confirmed the reliability and stability of the questionnaire with its three subscales.

The first factor identified contains items covering health reasons for weight loss. Given that in previous research 50-
$85 \%$ of obese individuals trying to lose weight indicated health as their primary reason [19, 21-23], health seems indeed to be a strong motivator and its assessment based on a distinct subscale seems justified. Even though interviewees were also presented with items covering aspects of weight loss motivation due to advice from others ('because my general practitioner advised me to', 'because my partner is worried'), these items were not relevant for scale construction. Health thus seems to be a personal issue that might be more influenced by the short- and longer-term consequences of overweight and obesity than by pure advice obtained from others.

The second factor deals with items focusing on the improvement of human relationships due to weight loss and was therefore named 'appearance in relation to others'. The importance of such a factor is clearly supported by research on quality of life, stigmatization, and career problems of overweight and obese patients [7-9]. By losing weight these individuals hope to handle the weight-related problems they are confronted with in their daily social interactions.

The third factor refers to overweight and obese individuals' wishes to be more attractive and more likeable to themselves. This factor seems to reflect individuals' own body dissatisfaction, which they hope to improve by losing weight [37], and was thus labeled 'appearance in relation to oneself'. Although in both CFAs (survey 1 and first wave of survey 2), the second and third factor were more highly correlated than either of these two factors with the first, the identification of two distinct appearance-related factors seems warranted, as the correlation was less than 0.8 and significantly lower than 1 for both surveys. 
Multigroup analyses showed that factor loadings as well as factor variances and covariances did not differ between the subgroups defined for age, BMI and regional language, which justifies the generalizability of the three factors across ages and between non-obese and obese patients as well. These findings should, however, be interpreted with caution as the sample size, especially regarding the subgroups with $\mathrm{BMI} \geq 30$ $\mathrm{kg} / \mathrm{m}^{2}(\mathrm{n}=65)$ and the French-speaking region $(\mathrm{n}=83)$, was small, thus impeding the detection of non-invariance. Thus, our questionnaire should be further validated in an enlarged sample of obese patients. Regarding the sex subgroups, results from multigroup analyses rejected invariance among covariances for females and males. Males showed a particularly high correlation between the two factors dealing with appearance as the reason for weight loss. It can be suggested that men might be less susceptible for societal pressure to be thin than woman and thus might focus less on different aspects of appearance. In contrast, females showed a particularly high correlation between the factors health and appearance in relation to oneself as reasons for weight loss.

Several limitations of our study should be borne in mind: First, when we generated the 39 items for the survey, we did not have proved experts in this field who judged the suitability of our items. We were thus not able to assess the content validity of our scales [38]. Second, the sample sizes, especially of survey 2, were rather small for CFA, given the rough guideline of at least 5-10 cases for each parameter to be estimated, even though another rule of thumb states that sample sizes of 100-200 should be the lower limit [39]. Similar arguments can be made for multigroup analyses. Third, we did EFA and
CFA using the same sample from survey 1, but nevertheless cross-validation of the model with data from survey 2 supported the stability of our model. Fourth, the normal- or underweight interviewees of both surveys were not asked the questions regarding reasons for wanting to lose weight. So, our results are restricted to a population of overweight persons for whom weight loss is of primary importance regarding health and social consequences of overweight and obesity. Finally BMI values were based on self-reported information and might be distorted. Thus our prevalence rates of $36 \%$ of overweight or obese participants have to be handled with caution, even though the prevalence rates are comparable with prevalences in other European countries.

The reasons and motivating factors for participation in weight loss programs are meaningful characteristics of overweight and obese individuals, and guidelines suggest a pretreatment assessment [18]. The 24-item questionnaire is the first validated assessment device in this area of research. As a next step it should be used in a clinical survey to assess its validity in treatment settings. In doing so, it could be used to target those individuals who may benefit from additional motivational work before starting a treatment, or to tailor interventions to participants' particular motivational reasons in order to increase adherence rates usually observed in weight loss treatments.

\section{Disclosure}

The authors declared no conflict of interest.

\section{References}

1 World Health Organization: Obesity: Preventing and Managing the Global Epidemic. Geneva, World Health Organization, 2004

$>2$ Becker ES, Margraf J, Turke V, Soeder U, Neumer $\mathrm{S}$ : Obesity and mental illness in a representative sample of young women. Int J Obes Relat Metab Disord 2001;25(suppl 1):S5-9.

$\checkmark 3$ Munsch S: Epidemiologie der Adipositas. Verhal tenstherapie 2002;12:278-287.

4 Visscher TL, Seidell JC: The public health impact of obesity. Annu Rev Public Health 2001;22:355-375.

$\checkmark 5$ Colditz GA: Economic costs of obesity and inactivity. Med Sci Sports Exerc 1999;31:S663-667.

6 Hopman WM, Berger C, Joseph L, et al: The association between body mass index and health-related quality of life: data from CaMos, a stratified population study. Qual Life Res 2007:16:1595-1603.

7 Schwimmer JB, Burwinkle TM, Varni JW: Healthrelated quality of life of severely obese children and adolescents. JAMA 2003;289:1813-1819.

$\checkmark 8$ Gortmaker SL, Mist A, Perrin JM, Sobol AM, Dietz WH: Social and economic consequences of overweight in adolescence and young adulthood. N Engl J Med 1993;329:1008-1012.

$\checkmark 9$ Puhl RM, Heuer CA: The stigma of obesity: a review and update. Obesity 2009;17:941-964.
10 Serdula MK, Mokdad AH, Williamson DF, Galuska DA, Mendlein JM, Heath GW: Prevalence of attempting weight loss and strategies for controlling weight. JAMA 1999;282:1353-1358.

11 Wardle J, Johnson F: Weight and dieting: examining levels of weight concern in British adults. Int $\mathrm{J}$ Obes Relat Metab Disord 2002;26:1144-1149.

12 Wee CC, Davis RB, Phillips RS: Stage of readiness to control weight and adopt weight control behaviors in primary care. J Gen Intern Med 2005;20: 410-415.

13 Crawford D, Jeffery RW, French SA: Can anyone successfully control their weight? Findings of a three year community-based study of men and women. Int J Obes Relat Metab Disord 2000;24:1107-1110.

14 Flegal KM, Carroll MD, Ogden CL, Johnson CL: Prevalence and trends in obesity among US adults, 1999-2000. JAMA 2002;288:1723-1727.

15 Wing RR, Hill JO: Successful weight loss maintenance. Annu Rev Nutr 2001;21:323-341.

16 Teixeira PJ, Going SB, Sardinha LB, Lohman TG: A review of psychosocial pre-treatment predictors of weight control. Obes Rev 2005;6:43-65.

17 Wadden TA, Foster GD: Behavioral treatment of obesity. Med Clin North Am 2000;84:441-461, vii.
18 National Institutes of Health, National Heart, Lung, and Blood Institute, North American Association for the Study of Obesity: Practical Guide to the Identification, Evaluation, and Treatment of Overweight and Obesity in Adults. Washington DC, Department of Health and Human Services, Public Health Service, 2000.

19 Hankey CR, Leslie WS, Lean ME: Why lose weight? Reasons for seeking weight loss by overweight but otherwise healthy men. Int J Obes Relat Metab Disord 2002;26:880-882.

20 Cheskin LJ, Donze LF: msJAMA: Appearance vs health as motivators for weight loss. JAMA 2001; 286:2160.

21 Dalle Grave R, Calugi S, Magri F, et al: Weight loss expectations in obese patients seeking treatment at medical centers. Obes Res 2004;12:2005-2012.

22 O'Brien K, Venn BJ, Perry T, et al: Reasons for wanting to lose weight: different strokes for different folks. Eat Behav 2007;8:132-135.

23 Reas DL, Masheb RM, Grilo CM: Appearance vs. health reasons for seeking treatment among obese patients with binge eating disorder. Obes Res 2004;12:758-760.

24 Putterman E, Linden W: Appearance versus health: does the reason for dieting affect dieting behavior? J Behav Med 2004;27:185-204. 
25 Brink PJ, Ferguson K: The decision to lose weight. West J Nurs Res 1998;20:84-102.

26 Brownell K, Hager DL, Leermakers E: The Weight Loss Readiness Test II - 2004, Version 4.1. Dallas, American Health Publishing, 1990.

27 Kline R: Principles and Practice of Structural Equation Modeling. New York, Guilford Press, 1998.

28 Floyd FJ, Widaman KF: Factor analysis in the development and refinement of clinical assessment instruments. Psychol Assess 1995;7:286-299.

29 Horn JL: A rationale and test for the number of factors in factor analysis. Psychometrika 1965;30 179-185.

30 Byrne B: Testing for multigroup invariance using AMOS Graphics: a road less traveled. Structural Equation Modeling 2004;11:272-300.
31 SPSS: SPSS for Mac OS X, Rel. 14.0.0. Chicago, SPSS, Inc., 2006.

32 Arbuckle J: Amos Users' Guide: Version 3.6. Chicago, SmallWaters Corp., 1997.

33 Cronbach LJ: Coefficient alpha and the internal structure of tests. Psychometrika 1951;16:297-334.

34 Bland JM, Altman DG: Statistical methods for assessing agreement between two methods of clinical measurement. Lancet 1986;i:307-310.

35 Vandiver B, Cross WE, Worrell FC, Fhagen-Smith PE: Validating the cross racial identity scale. J Consult Clin Psychol 2002;49:71-85.
36 Nunnally JC, Bernstein IH: Psychometric Theory, 3rd ed. New York, McGraw-Hill, 1994.

37 Sarwer DB, Wadden TA, Foster GD:Assessment of body image dissatisfaction in obese women: specificity, severity, and clinical significance. J Consult Clin Psychol 1998;66:651-654.

38 Hinkin T: A review of scale development practices in the study of organizations. J Manage 1995;21: 967-988.

39 Brown TA: Confirmatory Factor Analysis for Applied Research. New York, Guilford Press, 2006. 